\title{
New Approach for Getting Better Bandwidth in Wireless Mobile Computing
}

\author{
Anirban Chakraborty, Bhupinder Kaur, Ruchika
}

\begin{abstract}
Wireless mobile computing is type of computation by which various mobile gadgets gives services to us at numerous ways. In wireless computing of mobile one can find the working of sensors ad hoc networks odysseys and rover etc. Not only has this wireless based mobile computing service also suggested that a user can take the services of networks any time anywhere without any disturbances[1]. This includes the physical location time place authentication etc. which paves way for making mobile services successful. The research paper also describes about merits and disadvantages of wireless mobile computing along with many challenges faced by it in remote areas. Additionally, this paper also states how we get adapted to the ecosystem of wireless network from the long process of wired networks. Mobile agent is one of the most important elements in computing. It is clearly described in this research paper. This research paper also throws ample amount of light on the working of sensors and its unique features[12]. Wireless computing makes our life totally comfortable by its outstanding services. Here all useful services of that are clearly mentioned. At last the conducting of wireless mobile computing in all areas of the world is much more important for the welfare of future generations [9]. This research paper describes about the steps with measures needed in implementing wireless computing everywhere.
\end{abstract}

KEYWORDS- Mobile, Computing, Odessey, Rover, Agent, Sensor.

\section{INTRODUCTION}

Mobile Computing generally means transferring of data, music, video etc. in wireless medium in less time[2]. It is a new method for getting all the wired services we use to get earlier but this time we can get all the mobile services from any places. We need not to go in particular places to get the particular service.

\section{Manuscript received 13 July, 2020}

Anirban Chakraborty, M.Tech, Department of Artificial Intelligence, Lovely Professional University, Phagwara, Punjab, India, Mob- +91 8731032036 (e-mail: anirbanchakraborty456@gmail.com)

Bhupinder Kaur, M.Tech, Department of Computer Science \& Engineering, Lovely Professional University, Phagwara, Punjab, India

Ruchika, M.Tech, Department of Computer Science And Engineering, Lovely Professional University, Phagwara, Punjab, India
Mobile Computing reduces human effort as most of the work is either done by Robots whom do we called Artificial Intelligence and also some works are done by Sensors. In mobile computing adaptation is very important as is most of the cases network becomes weak suddenly. So static network is not possible in case of wireless services rather we have to adapt dynamically. There are two models of Mobile Computing[3] which states that how to adapt to a network of good bandwidth for better connection and performance. Highlight a section that you want to designate with a certain style, and then select the

These two models are:

- ODESSEYMODEL

- ROVERMODEL

These models are described elaborately below. Sensor Networks [5] plays an important role in Mobile Computing. Sensors are nowadays used in every crucial and important works as it gives an accurate work. Mobile Computing is a boon for human society.

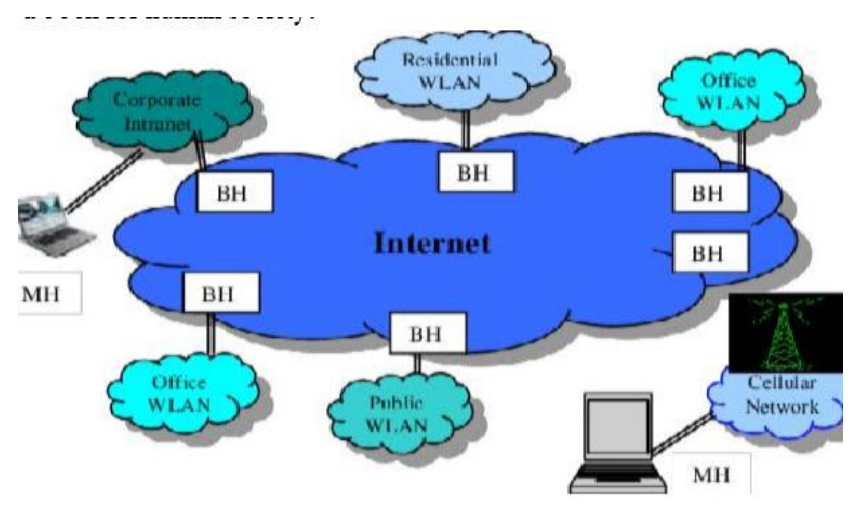

Fig 1: Mobile Computing over a Network

\section{OBJECTIVES}

There are many objectives of Mobile Computing. It helps common people in many ways giving a large number of services. The aim of Mobile Computing is to:

- Application Context Adaptation

- Application Transparent Adaptation

- More reliability

- More security

- Cloud Computing

- Infrastructure less computing

- Rich network connection

- High bandwidth

It promises every user to provide seamless computing services. Government is also working hard to implement 


\section{New Approach for Getting Better Bandwidth in Wireless Mobile Computing}

Mobile Computing Services in every part of the world.

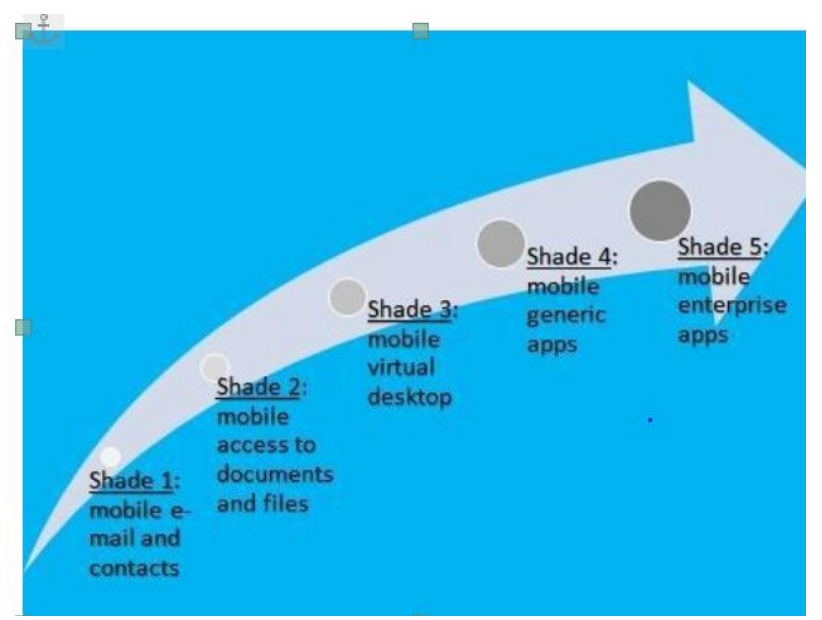

Fig 2: Cloud Computing

\section{METHODS AND METHODOLOGIES}

There are mainly two methods in good Mobile computing. These are generally two models which paved the way of Mobile Computing successful. These are very helpful in the areas of low connectivity.

\section{A. ODESSEY}

Viceroys[4] performs the main responsibility in handling all the request of service callback and network related issues. It monitors all the useful events occurring in time of network procedure calls. Here Wardens are responsible for handling all the data types needed during strong network connection. Client first contact with warden and then Warden Contact with Vice Roy if any problem occurs. All the queries have to pass through Odessey[11] call for approval. This technique is widely used to get a strong connection with greater bandwidth.

\section{B. ROVER}

Rover[7] is an article based programming unit for making both portability mindful and versatility straightforward CS disseminated applications. It gives application engineers with programming and correspondence reflections explicitly made for helping applications in cruel system situations, for example, portable figuringrelocatable unique articles (RDO) and lined remote methodology calls (QRPC). RDOs can be utilized to diminish associations between two pitifully associated elements, for example, a customer on the cell phone and a server in the wire line arrange. Wanderer RDOs are objects with all around characterized interfaces and are loadable powerfully from the server to the customer. This moves articles to the customer machine, securing the customer speaking with the item at the server. QRPCs can be utilized to deal with separations. Wanderer QRPCs are basically non-blocking remote method calls (RPCs) that help split-stage activities. They enable an application to make a RPC without stressing over whether the goal is at present reachable. In the event that the goal of the RPC isn't reachable at the hour of the call, the call is lined. On reconnection to the RPC's goal, the RPC is performed[6].

\section{HYPOTHESIS}

There are many Hypotheses regarding the working of

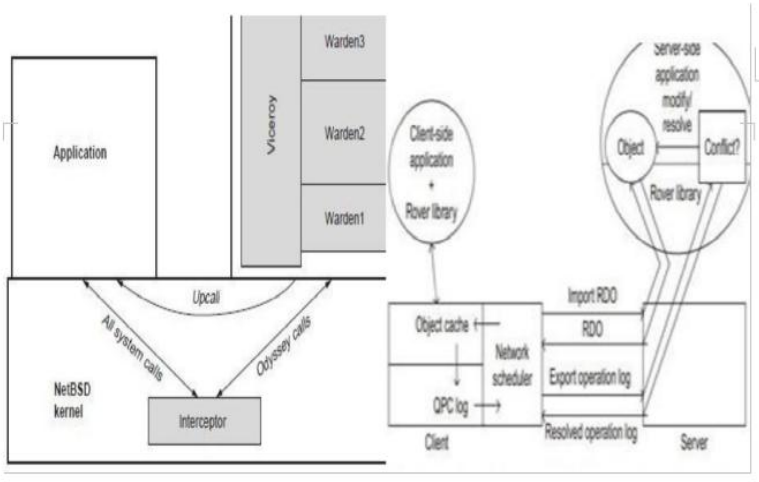

Fig 3: Odessey and Rover

Mobile Computing devices. Many engineers proposed many methods to get huge bandwidth and to prepare a good network connection. According to the research work done by me, I have found some hypothesis which will give better bandwidth to establish a good connection. These are as follows when a portable square is turned on, the HLR is informed of the present area of $m$ (the cell where the versatile square is found). The portable hub m's area is sent to the area server. The enrollment message goes by the base station of the cell to the area server[8].

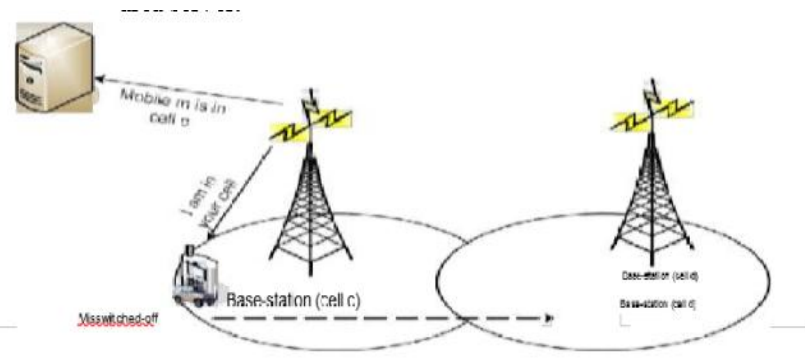

Fig 4: Registration upon Mobile Switching On

At whatever point handoff happens, the HLR is notified of the cell ID to which $m$ is giving off to. At the point when the versatile hub moves to cell $\mathrm{d}$ from cell $\mathrm{c}$, the portable hub may choose to enlist its area to be cell d.

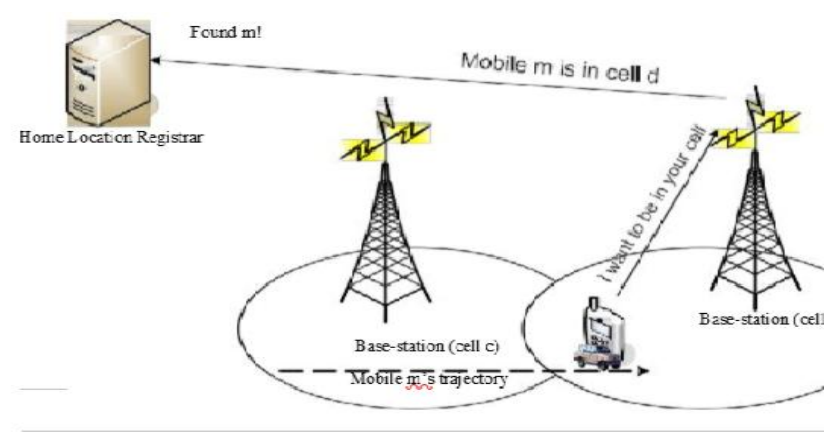

Fig 5: Registration upon Cell Handoff

To locate a portable hub m's present area, first the HLR is reached. The HLR contacts the base station of cell $\mathrm{c}$ in 
the versatility authoritative form. The base station pages for portable $\mathrm{m}$ in its cell. On the off chance that $\mathrm{m}$ is in cell $\mathrm{c}$ and is turned on, at that point it can react to the page message, and association can be built up. The underneath figure shows the informing between different elements in this area the board plot[9].

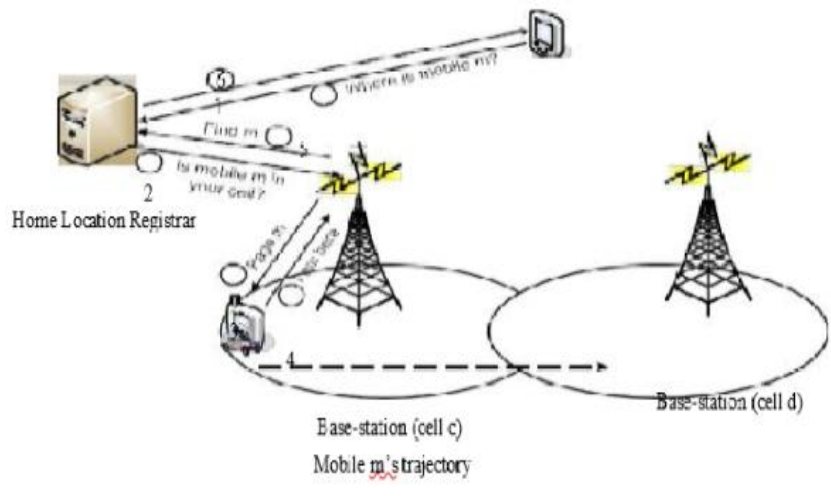

Fig 6: Finding m- success case

When the phone of $M$ is off then Internet Service Provider dynamically updates the location of the user to get better networks[14].

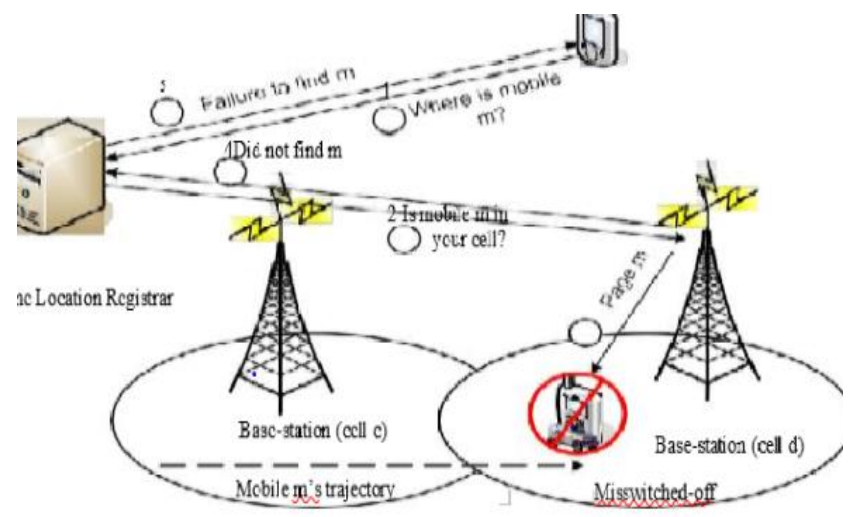

Fig 7: Finding m- failure case

These are generally done by Handoffs[15]. Handoffs dynamically update the location of mobile nodes. In my research work we search about handoffs and found that there are three types of handoffs which are:

- Mobile Controlled Hand-off

- Network Controlled Hand-off

- Location Controlled Hand-off.

\section{CHALLENGES AND LIMITATIONS}

In time of researching, it's found that there are many challenges mobile computing has to face with. These challenges need to be successfully abolished to make computing services[12] more innovative. Some of the important challenges it faced are:
1. Mobile computers can be more resource poor then the wired computers.

2. They needs battery sources to run so battery needs to replaced or recharged

3. Mobile computing is little costlier

4. They are less secure and less reliable

5. Mobile computers are dynamic in nature so they are bound to be lost or taken

6. Sometimes bandwidth becomes very less so network problems occurs.

7. Moreover, the internet service providers should be much aware about the bandwidth problem.

We researched and got a number of options to overcome this challenges in which ROVER toolkit is the best.

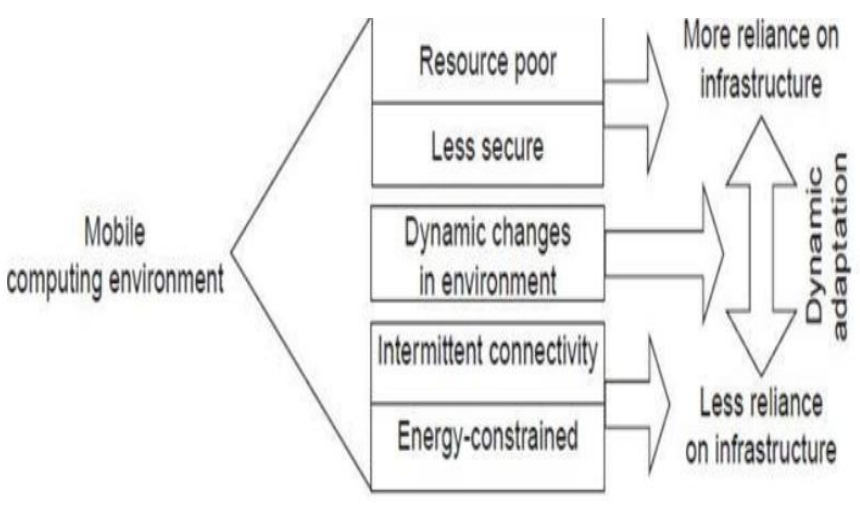

Fig 6: Dynamic Adaptation

\section{WIRELESS SENSOR NETWORKS}

Sensor networks are one of the most important parts of mobile computing. Sensors have many useful applications:

- Medical applications: Sensors are used by doctors for diagnosis of cancer, measuring blood sugar etc.

- Industrial applications: Sensors can be used in shops at barcodes to identify every product accurately.

- Military applications: Sensors are now used in landmine detection, tracking of works of enemies etc.

Sensors are embedded in the environment to calculate many computing calculations along with logical reasoning and it performs satisfactory. Mainly LEACH protocol[10] is used where a single node is made Cluster Head and other subsequent nodes transmit the data to the cluster head and cluster head passes to the base station. In this way sensor is working to provide a better result.

\section{RESULTS}

Results have been found regarding research works done. It clearly states that the future will be of mobile computing and the most important factor will be a good bandwidth. To get huge bandwidth two modes are introduced namely:

- PUSH mode: It is known as public subscribe mode. It is very resource efficient and scalable. That's why the bandwidth will always be high.

- PULL mode: It is known as on demand mode. Here 


\section{New Approach for Getting Better Bandwidth in Wireless Mobile Computing}

client first send query then server sent the necessary data. So uplink and downlink is of very high bandwidth.

\section{OBSERVATIONS}

Bandwidth allocation[13] is calculated properly. We have used the best method to get huge bandwidth and it is PUSH mode and PULL mode.

Bandwidth Allocation

Bandwidth for on-demand channel $-\mathrm{Ba}$

Bandwidth for broadcast channel $-\mathrm{Bc}$

Available bandwidth $\mathrm{B}=\mathrm{Ba}+\mathrm{Bc}$

Data Server

K data items: $\mathrm{X} 1, \mathrm{X} 2, \ldots, \mathrm{Xn}$

$\mathrm{X} 1$ - the most popular data items, with popularity ratio Q1 (between 0 and1)

$\mathrm{X} 2$ - the next popular data item with popularity ratio Q2 (between 0 and1)

Size for each data item $-\mathbf{J}$

Size of each data query -L

Each mobile node generates requests at an average rate of L.

Compute Average Access Time T over all data items $\mathrm{T}=\mathrm{Tc}+\mathrm{Ta}$

Tc - average access time to access a data item

from the broadcast channel

$\mathrm{Ta}$ - average access time to access an on demand item

The Average Time to service an on-demand request $(\mathrm{J}+\mathrm{L}) / \mathrm{Ba}$

If all data items are provided only on-demand, the average rate for all the on-demand items will be

$\mathrm{H} \times 1$ (queuing generation rate)

$\mathrm{H}-$ the number of mobile nodes in the wireless cell

1 -average request rate of a mobile node. Applying Queuing Theory to Analyze the Problem

As the number of mobile users $\uparrow($ increases), $->$ the average queue generation rate becomes $(\mathrm{Hx} \mathrm{l}) \uparrow$. As $(\mathrm{H} \mathrm{x}$ 1) approaches $\rightarrow$ the service rate becomes $[\mathrm{Ba} /(\mathrm{J}+\mathrm{L})],->$ the average service time increases (including queuing delay) $\uparrow$ rapidly.

What is acceptable server time threshold?

Allocating all the bandwidth to the on- demand channels $\rightarrow$ Poor Scalability.

If all the data items are published on the broadcast channel with the same frequency (ignoring the popularity ratio).

Average waiting: $\mathrm{n} / 2$ data items

Average access time for a data item: $(\mathrm{k} / 2) \times(\mathrm{L} / \mathrm{Bc})$

Independent of number of mobile nodes in the cell Average access time proportional to the number of data items $\mathrm{k}$.

Average Access Time $\uparrow$ as the number of data items to broadcast.

Two data items: D1 andD2

$\mathrm{Q} 1$ of X1 > Q2 of X2 (X1 is more popular than X2)

Temp to broadcast $\mathrm{X} 1$ all the time $\rightarrow$ cause $\mathrm{X} 2$ access time to be infinite ( $\mathrm{X} 2$ is never available)

Broadcast frequency calculation to achieve minimum average access time

$$
\begin{aligned}
& \mathrm{F} 1=\sqrt{ } \mathrm{Q} 1 /(\sqrt{ } \mathrm{Q} 1+\sqrt{\mathrm{Q} 2}) \\
& \mathrm{F} 2=\sqrt{\mathrm{Q} 2} /(\sqrt{\mathrm{Q} 1}+\sqrt{\mathrm{Q} 2}) \\
& \text { An example: } \mathrm{P} 1=0.9, \mathrm{P} 2=0.1
\end{aligned}
$$

D1 broadcast 3-times more often than D2,

D1 is 9- times more popular thanD2

$\mathrm{N}$ data items: $\mathrm{X} 1, \mathrm{X} 2, \ldots, \mathrm{Xn}$

Popularity Ratio: Q1, Q2, ..,Qn

Broadcast Frequencies: F1,F2,

$\mathrm{Fn}($ min latency $)=$

$\sqrt{ } \mathrm{Q} / \mathrm{Z}, \mathrm{Z}=\sqrt{\mathrm{Q} 1}+\sqrt{\mathrm{Q} 2}+\ldots \mathrm{Qn}$

Minimum latency: P1*t1 + Q2*t2 +... Qn*tn ,t1, t2, $\ldots, t \mathrm{tn}$ are average access latencies of X1, X2, ., Xn.

8. Algorithm Generation

This algorithm is better for getting good bandwidth.

For $\mathrm{i}=\mathrm{N}$ down to $1 \mathrm{do}$ :

Begin

Assign $\mathrm{X} 1, \ldots, \mathrm{Xi}$ to the broadcast channel

Assign $\mathrm{Xi}+1, \ldots, \mathrm{XN}$ to the on-demand channel

Determine the optimal value of $\mathrm{Bc}$ and $\mathrm{Ba}$, to minimize the access time $\mathrm{T}$, as follows

Compute To by modeling on-demand channel[6] as $\mathrm{H} / \mathrm{H} / 1$ (or $\mathrm{H} / \mathrm{X} / 1$ )queue Compute Tc by using the optimal broadcast frequencies $\mathrm{F} 1, \ldots, \mathrm{Fi}$ Compute optimal value of $\mathrm{Bb}$ which minimizes the function $\mathrm{T}=\mathrm{Ta}+\mathrm{Tc}$.

if $\mathrm{T}<=\mathrm{E}$ then break End

\section{CONCLUSION}

Mobile computing is really very much needed in humans life as it can make all data related works and services more efficiently. During the research we found almost every person is dependent in mobile computing. So we have made some algorithms and observations to make mobile computing more easy and convenient.

\section{REFERENCES}

[1] Alles, N., Soysa, N., Hayashi, J., Khan, M., Shimoda, A., Shimokawa, H., Ritzeler, O., Akiyoshi, K., Aoki, K., Ohya, K., 2010. Suppression of NF-kappaB increases bone formation and ameliorates osteopenia in ovariectomized mice. Endocrinology 151, 46264634.

[2] Almeida, M., O’Brien, C.A., 2013. Basic biology of skeletal aging: role of stress response pathways. J. Gerontol. A: Biol. Sci. Med. Sci. 68, 1197-1208.

[3] Altindag, O., Erel, O., Soran, N., Celik, H., Selek, S., 2008. Total oxidative/anti-oxidative status and relation to bone mineral density in osteoporosis. Rheumatol. Int. 28, 317-321.

[4] Baek, K.H., Oh, K.W., Lee, W.Y., Lee, S.S., Kim, M.K., Kwon, H.S., Rhee, E.J., Han, J.H., Song, K.H., Cha, B.Y., Lee, K.W., Kang, M.I., 2010. Association of oxidative stress with postmenopausal osteoporosis and the effects of hydrogen peroxide on osteoclast formation in human bone marrow cell cultures. Calcif. Tissue Int. 87, 226-235.

[5] Bai, X.C., Lu, D., Bai, J., Zheng, H., Ke, Z.Y., Li, X.M., Luo, S.Q., 2004. Oxidative stress inhibits osteoblastic differentiation of bone cells by ERK and NF-kappaB. Biochem. Biophys. Res. Commun. 314, 197-207. 
[6] Burge, R., Dawson-Hughes, B., Solomon, D.H., Wong, J.B., King, A., Tosteson, A., 2007. Incidence and economic burden of osteoporosis-related fractures in the United States, 2005-2025. J. Bone Miner. Res. 22, 465-475.

[7] Busino, L., Millman, S., Scotto, L., Kyratsous, C., Basrur, V., O’Connor, O., Hoffmann, A., ElenitobaJohnson, K., Pagano, M., 2012. Fbxw7alpha- and GSK3-mediated degradation of p100 is a prosurvival mechanism in multiple myeloma. Nat. Cell Biol. 14, 375-385.

[8] Cervellati, C., Bonaccorsi, G., Cremonini, E., Romani, A., Fila, E., Castaldini, M.C., Ferrazzini, S., Giganti, M., Massari, L., 2014. Oxidative stress and bone resorption interplay as a possible trigger for postmenopausal osteoporosis. Biomed. Res. Int. 2014, 569563.

[9] Chang, J., Wang, Z., Tang, E., Fan, Z., McCauley, L., Franceschi, R., Guan, K., Krebsbach, P.H., Wang, C.Y., 2009. Inhibition of Osteoblast Functions by IKK/NF-jB in Osteoporosis. Nat. Med. 6, 682-689.

[10]Guillerminet, F., Beaupied, H., Fabien-Soulé, V., Blais, A., 2010. Hydrolyzed collagen improves bone metabolism and biomechanical parameters in ovariectomized mice: an in vitro and in vivo study. Bone 46, 827-834.

[11]Hamada, Y., Fujii, H., Fukagawa, M., 2009. Role of oxidative stress in diabetic bone disorder. Bone 45 (Suppl. 1), S35-S38.

[12]Hendrickx, G., Boudin, E., Van Hul, W., 2015. A look behind the scenes: the risk and pathogenesis of primary osteoporosis. Nat. Rev. Rheumatol. 11, 462474Huang, Q., Gao, B., Jie, Q., Wei, B.Y., Fan, J., Zhang, H.Y., Zhang, J.K., Li, X.J., Shi, J., Luo, Zh.J., Yang, L., Liu, J., 2014. Ginsenoside-Rb2 displays anti-osteoporosis effects through reducing oxidative damage and bone-resorbing cytokines during osteogenesis. Bone 66, 306-314.

[13]imi, E., Fukushima, H., 2016. NF-kappaB signaling pathways and the future perspectives of bone disease therapy using selective inhibitors of NF-kappaB. Clin. Calcium 26, 298-304.

[14]Kadenbach, B., Ramzan, R., Vogt, S., 2009. Degenerative diseases, oxidative stress and cytochrome c oxidase function. Trends Mol. Med. 15, 139-147.

[15]Kim, H.K., Kim, M.G., Leem, K.H., 2013. Osteogenic activity of collagen peptide via ERK/MAPK pathway mediated boosting of collagen synthesis and its therapeutic efficacy in osteoporotic bone by back-scattered electron imaging and microarchitecture analysis. Molecules 18, 1547415489. 